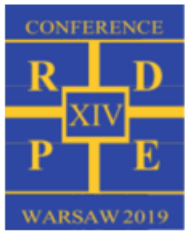

\title{
EXERGY-BASED INVESTIGATION OF A COAL-FIRED ALLAM CYCLE
}

\author{
Jing L uo ${ }^{1,}{ }^{*}$, Ogechi Emelogu ${ }^{1}$, Tatiana M orosuk $^{2}$, and George Tsatsaronis ${ }^{2}$ \\ 1,2 Technical University of B erlin, Institute for Energy Engineering, M archstr. 18, 10587, B erlin, Germany \\ E-mail: ¿ing.luo@campus.tu-berlin.de; emelogu.ogechi@gmail.com; tetyana.morozyuk@tu-berlin.de; \\ tsatsaronis@mailbox.tu-berlin.de
}

\begin{abstract}
Allam cycle is a novel cycle that capitalizes on the unique thermodynamic properties of supercritical $\mathrm{CO}_{2}$ and the advantages of oxy-combustion for power generation. It is a high-pressure supercritical carbon dioxide cycle designed to combust fossil fuels such as natural gas or syngas (from coal gasification systems) with complete $\mathrm{CO}_{2}$ separation at a high-efficiency and zero atmospheric emissions. This semi-closed cycle produces sequestration-ready/pipeline quality $\mathrm{CO}_{2}$ by-product, and thus eliminates the need for additional $\mathrm{CO}_{2}$-capture system. The Coal-fuel ed Allam cycle is targeted to deliver between $51-52 \%$ net efficiency (lower heating value) for coal gasification. In this study, the expected energetic efficiency is verified by simulating the system in Ebsilon professional software and the result show ed that the net efficiency of the simulated coal-fired plant is $30.7 \%$, which is significantly lower than the targeted value. The lower efficiency maybe as a result of the missing heat integration in the system, the high power demand of the oxidant compressor and $\mathrm{CO}_{2}$ compressors. And an exergy analysis based on published cycle data is employed, to investigate the cycle performance, identify the sources of the cycle's thermodynamic inefficiencies at the component level; a sensitivity analysis is also performed to study the effects of selected thermodynamic parameters on the overall performance of the coal-fired Allam cycle.
\end{abstract}

\section{Introduction}

Coal is regarded as one of the largest resources for power generation worldwide. A ccording to International Energy A gency (IEA), coal-fired power generation increased by approximately 3\% in 2017 and in 2018, reaching a new peak above 10,000 TWh [1]. Globally, over $30 \%$ of the global energy demand and over $40 \%$ of the electricity generated is derived from coal, owing to the fact that it is a secure and relatively low-cost source of energy, and the resources are abundant and broadly distributed geographically [2]. However, with the significantly increasing demand in global energy, comes the challenge of increasing $\mathrm{CO}_{2}$ emissions, of which coal-fired power plants are major contributors.

In a bid to reduce $\mathrm{CO}_{2}$ emissions from power generating plants, several solutions have been proposed and developed. The carbon capture and storage (CCS) is one of such. Incorporation of this solution however, presents detrimental efficiency penalty and increased price of electricity due to the high cost of additional equipment. Therefore, novel technologies that generate electricity from coal with reduced $\mathrm{CO}_{2}$ emissions and high efficiency are being developed.

The core Allam cycle was developed and patented by Rodney Allam in 2013 and demonstrated with natural gas by NET Power LLC. It capitalizes on the unique thermodynamic properties of supercritical $\mathrm{CO}_{2}$ as a working fluid in an oxy-combustion processes for power generation, is one of such promising technologies. This semi-closed cycle employs high-pressure supercritical $\mathrm{CO}_{2}$ in a highly recuperated cycle to reduce emissions, producing only pipeline grade $\mathrm{CO}_{2}$, hence eliminating the common necessity of additional capture, clean-up, and compression system [3]. The results of this technological setup include: significantly higher efficiencies, lower capital cost due to the simplicity of the Allam cycle core. The high efficiency stems from the moderate critical point of carbon dioxide at $30.98{ }^{\circ} \mathrm{C}$ and $73.8 \mathrm{bar}$, which compared to water can be easily compressed; as a result, the work of compression can be significantly reduced and invariably the plant efficiency enhanced [4].

In 2016, Lu et al. [5] introduced the coal variant of the Allam cycle system; the study focused on the unique considerations, possible hurdles and the advantages of integrating a commercially-available gasifiers with the Allam cycle. The efficiency of the Coal Allam cycle varied between $43.3 \%$ - $49.7 \%$ ( $\mathrm{HHV}$, or $45 \%-52 \%$ on the LHV basis).

\section{System Description}

In order to utilize coal, the core Allam cycle requires several additional units, namely:

a) a coal gasifier and ancillary systems (to produce clean syngas) 
b) Syngas pre-combustion clean up systems and post-combustion clean-up

c) Unique considerations for a syngas combustion turbine.

The power plant in the present study comprises of three (3) main subsystems: the coal gasification island, the supercritical $\mathrm{CO}_{2}$ power cycle, and the air separation unit (ASU) as shown in Fig. 1. It is based on the flow sheet proposed by Rodney et al. [6] with few variations which are described in subsequent sections.

Due to proprietary and intellectual property, detailed flow sheet, component assumptions and boundary conditions used in the design of Allam cycle are yet to be disclosed in literature. Hence, available process data [6-8] as well as best practice guidelines are used to obtain somewhat comparable results.

The environmental conditions according to [9] as well as the air compositions (default composition from Ebsilon professional software) are presented in Table 1 and 2 respectively. The composition of the coal (Table 3 ) used for the simulation is according to NETL's Quality Guidelines for Energy System Studies.
Table 1. Environmental conditions used for the simulation [9].

\begin{tabular}{|c|c|}
\hline \multicolumn{2}{|c|}{ Site Conditions } \\
\hline Ambient Pressure & 1.050 bar \\
\hline Ambient Temperature & $15.0^{\circ} \mathrm{C}$ \\
\hline Relative Humidity & $60 \%$ \\
\hline Cooling water temperature & $15.0{ }^{\circ} \mathrm{C}$ \\
\hline
\end{tabular}

Table 2. Air composition ${ }^{\mathrm{a}}$

\begin{tabular}{|c|l|}
\hline \multicolumn{2}{|c|}{ Air Composition } \\
\hline Nitrogen & 0.7544 \\
\hline Oxygen & 0.2312 \\
\hline Argon & 0.1289 \\
\hline Carbon Dioxide & 0.0004995 \\
\hline Water & 0.001000 \\
\hline
\end{tabular}

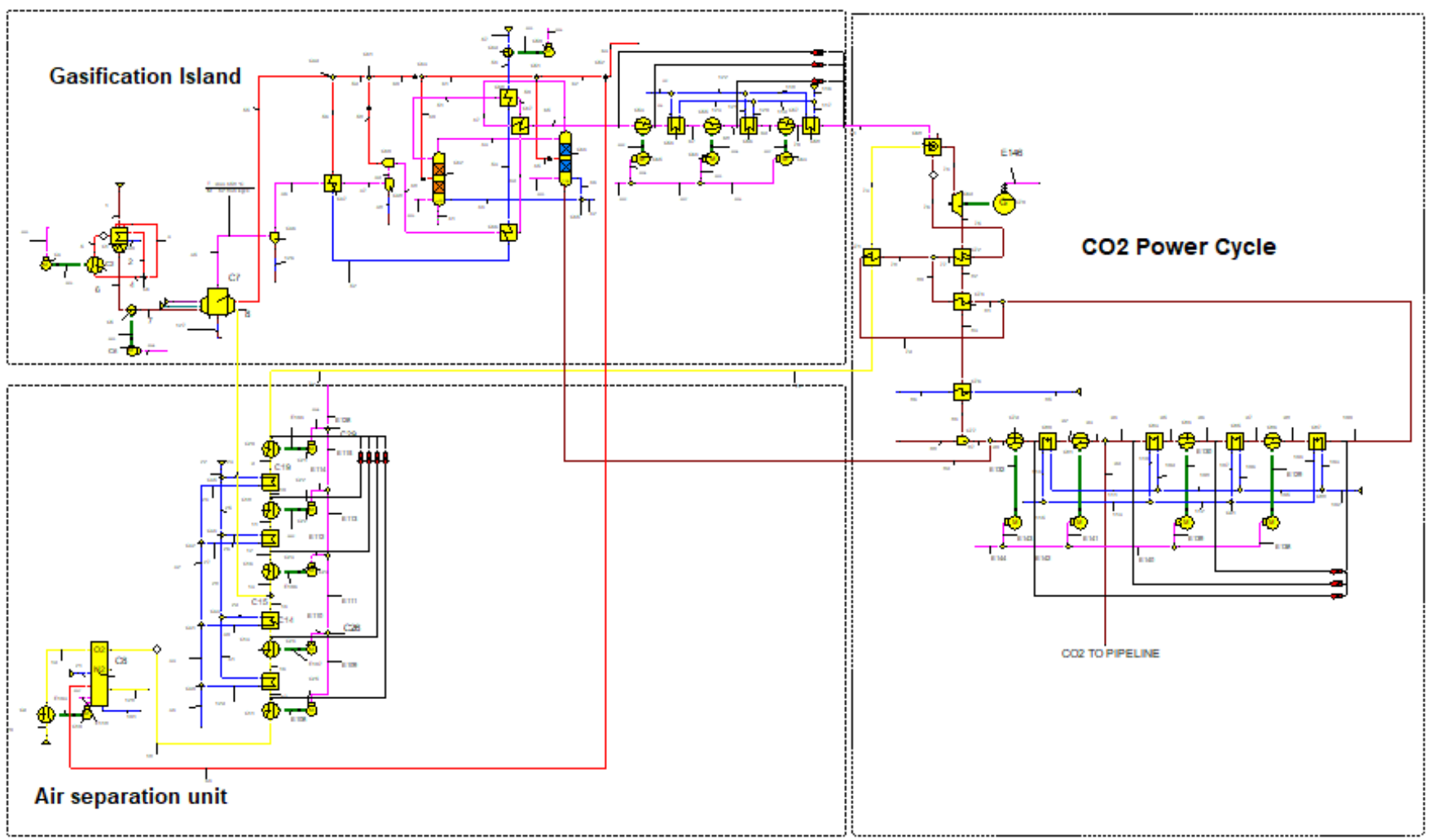

Fig. 1. Flowsheet of the Coal-fired Allam cycle simulated in Ebsilon

\footnotetext{
${ }^{\text {a } A c c o r d i n g ~ t o ~ t h e ~ d e f a u l t ~ a i r ~ c o m p o s i t i o n ~ i n ~ E b s i l o n ~}$ professional
} 
Table 3. Bituminous Coal Composition [10]

\begin{tabular}{|c|c|}
\hline \multicolumn{2}{|c|}{ Coal Composition } \\
\hline Ultimate analysis & As received, wt $\%$ \\
\hline Carbon & 63.75 \\
\hline Hydrogen & 4.50 \\
\hline Nitrogen & 1.25 \\
\hline Sulfur & 2.51 \\
\hline Chlorine & 0.29 \\
\hline Ash & 9.70 \\
\hline M oisture & 11.12 \\
\hline Oxygen & 6.88 \\
\hline
\end{tabular}

The coal is dried by steam to $5 \%$ moisture content and is then fed to the gasifier. The steam and the oxygen (from the ASU) needed for the gasification process are also fed into the gasifier. The produced fuel gas passes through a series of heat exchangers, fine particle filters and acid gas removers to absorb $\mathrm{CO}_{2}$ and $\mathrm{H}_{2} \mathrm{~S}$. The cleaned syngas is then compressed and sent to the combustor of the power cycle where it reacts with pure oxygen and recycled $\mathrm{CO}_{2}$. The turbine inlet temperature of $1150{ }^{\circ} \mathrm{C}$ by controlling the mass flow rate of the recycled $\mathrm{CO}_{2}$.

The air separation unit is modelled as a black box, with specific power demand specified in order to calculate the power that must be supplied by the main cycle. The pure oxidant stream exiting the ASU is split into two streams, one to be fed into the coal gasifier and the other, to the oxidant compression train. In order to limit the net power consumption of the oxidant compressors, a multistage compression with interstage cooling is employed. The residual heat of compression is transferred to a recycle $\mathrm{CO}_{2}$ stream, lowering the temperature of the pure oxygen fed into the combustor to $750{ }^{\circ} \mathrm{C}$. The supercritical $\mathrm{CO}_{2}$ $\left(\mathrm{SCO}_{2}\right)$ power cycle is modelled according to the $\mathrm{SCO}_{2}$ power cycle of the pulverized coal power station retrofit example in [6].

A fter leaving the heat exchangers, the flue gas is further cooled to condense water contained within the stream. A selective splitter is used to separate liquid, and gaseous water, unburnt oxygen and nitrogen, leaving the flue gas as a pure $\mathrm{CO}_{2}$ stream. This $\mathrm{CO}_{2}$ stream is then compressed using a multistage inter-cooled compressor, to the needed high pressure, thus closing the power cycle.

\section{Methodology}

The Ebsilon Professional software was used for the simulation of the coal-fired Allam cycle and the Microsoft Visual Basic Application (VBA) was used to conduct the exergetic analysis of the stream and the components. Ebsilon professional provides information about the thermodynamic efficiency of the system, while the Microsoft VBA tool was used obtain the chemical exergy of the individual streams and to conduct the componentwise exergy analysis, this analysis provides detailed data about the main sources of inefficiencies within the cycle. The simulation parameters for the coal-fired Allam cycle are shown in table 4 below.

Table 4. Simulation parameters for the analysis of the coalfired Allam cycle

\begin{tabular}{|c|c|c|}
\hline Parameter & Value & Reference \\
\hline Turbine Inlet Temperature ${ }^{\circ} \mathrm{C}$ & 1200 & {$[7]$} \\
\hline Turbine Inlet Pressure bar & 300 & {$[7]$} \\
\hline Turbine Pressure Ratio & 10 & {$[7]$} \\
\hline Combustor Pressure drop \% & 1.6 & {$[7]$} \\
\hline $\begin{array}{c}\text { Oxygen Purity \% } \\
\text { ASU, Specific Power Demand } \\
\text { kWh/kgO } 2\end{array}$ & 99.5 & {$[11]$} \\
\hline $\begin{array}{c}\text { Generator efficiency } \\
\text { Compressor }\end{array}$ & 99 & {$[11]$} \\
\hline $\begin{array}{c}\text { Mechanical Efficiency for all } \\
\text { Compressor Isentropic Efficiency }\end{array}$ & 98 & {$[11]$} \\
\hline \multicolumn{2}{|c|}{} & \\
\hline
\end{tabular}

\subsection{Thermodynamic analysis}

In using the Ebsilon Professional modelling software, the mass and energy balances for the simulation model are solved. The electrical efficiency of the power cycle is defined as follows:

$$
\eta=\frac{\dot{W}_{n e t}}{\dot{m}_{f u e l} * L H V}
$$

The reference temperature and pressure used for the exergetic analysis are the same as listed in Table 1.

\subsection{Exergy Analysis}

Exergy analysis of a system provides vital information that reveal thermodynamic inefficiencies within a system, which are not obvious when analyzed using conventional thermodynamic analyses. It is defined as the maximum theoretical useful work obtained from a thermal system as it is brought into thermodynamic equilibrium with the environment while interacting with the environment only. Exergy can be destroyed within a system due to chemical reactions, friction, mixing of streams at different temperatures, pressure and composition and heat transfer.

The exergy of each stream is further split into its chemical and physical exergy as follows:

$$
\dot{\mathrm{E}}=\dot{\mathrm{E}}^{C H}+\dot{\mathrm{E}}^{P H}
$$

Since the process operates at steady-state conditions, the exergy balance of each component $k$ is used to calculate the exergy destruction peculiar to each component $k$. 


$$
\sum_{j} \dot{E}_{q, j, k}+W_{k}+\sum_{i} \dot{E}_{i, k}-\sum_{e} \dot{E}_{e, k}-\dot{E}_{D, k}=0
$$

To determine the real thermodynamic performance of a system's component $k$ as well as for the overall system, the exergy destruction $\dot{E}_{D, k}$ can further be used. The exergetic efficiencies of the $k$-th component $\varepsilon_{k}$ is calculated using the following equation:

$$
\varepsilon_{k}=\frac{\dot{E}_{P, k}}{\dot{E}_{F, k}}=1-\frac{\dot{E}_{D, k}}{\dot{E}_{F, k}}
$$

In addition to the exergy destruction that occurs within the system components, the analysis of possible exergy losses to the environment is also considered with the equation below.

$$
\varepsilon_{t o t}=\frac{\dot{E}_{P, t o t}}{\dot{E}_{F, t o t}}=1-\frac{\sum_{j} \dot{E}_{D, k}+\dot{E}_{L, t o t}}{\dot{E}_{F, t o t}}
$$

where $\dot{E}_{P, t o t}$ and $\dot{E}_{F, t o t}$ are the exergy rates of product and fuel of the overall system. The exergy rates $\dot{E}_{P, k}$ and $\dot{E}_{F, k}$ determine the respective exergy rates of product and fuel of a specific component $k$. By calculating the total component exergy destruction $\dot{E}_{D, k}$ and the exergy losses $\dot{E}_{L, t o t}$ of the overall system, the real thermodynamic efficiencies of the system are determined.

Another important parameter is the exergy destruction ratio $y_{D, k}$, which quantifies the contribution of the exergy destruction within a component $k$ to the reduction in the overall exergetic efficiency $\varepsilon_{t o t}$ of the system.

$$
\varepsilon_{t o t}=\frac{\dot{E}_{D, k}}{\dot{E}_{F, t o t}}
$$

Data obtained from the exergy analysis is used to define the thermodynamic performance of a system and the various components that make up the system.

\section{Results and Evaluation}

This section presents the findings of the thermodynamic and exergetic analysis of the coal-fired Allam cycle which forms the bedrock for further discussions on the effects of important process parameters on cycle performance.

\subsection{Results of simulation}

The net efficiency of the coal-fired Allam cycle in this study is $30.7 \%$; the principal parasitic loads of the plant (these were considered in the efficiency calculation) as shown in Table 5 below include: The A ir Separation U nit, the $\mathrm{CO}_{2}$, syngas, and oxidant compressor.

Table 6 shows the most important components in the exergetic analysis to be considered for improvement. The results of the exergetic efficiency as shown in table 6, indicate that the main inefficiencies can be found with the power cycle. The overall exergetic efficiency is $29 \%$. This means that only $29 \%$ of the available energy is converted into useful work. An exergetic efficiency of $29 \%$ is considerably low, implying that there are large amounts of inefficiencies within the system. Which are as a result of high destruction and losses. Exergy destruction within a component could be a function of friction and irreversibilities within the components and in the overall system itself, whilst losses are the heat transferred to the environment.

Table 5. Results of the simulation

\begin{tabular}{|c|l|c|}
\hline Parameter & Unit & Value \\
\hline Mass Flow Rate of Syngas & $\mathrm{Kg} / \mathrm{s}$ & 49.9 \\
\hline Gross energy produced (LHV) & {$[\mathrm{MW}]$} & 644.077 \\
\hline CO2 compression train & {$[\mathrm{MW}]$} & 142.393 \\
\hline Oxidant compression train & {$[\mathrm{MW}]$} & 119.218 \\
\hline Net Energy Produced & {$[\mathrm{MW}]$} & 255.643 \\
\hline Efficiency (LHV) & {$[\%]$} & 30.7 \\
\hline
\end{tabular}

The result in Table 5 shows that the net efficiency of the coal-fired plant is $30.7 \%$ which is significantly lower than the NETL reported value. The lower efficiency maybe as a result of the missing heat integration in the system, the high power demand of the oxidant compressor and $\mathrm{CO}_{2}$ compressors. In addition to this, the parameter uncertainty has a very huge influence on the efficiency.

Table 6. Results of exergy analysis

\begin{tabular}{|c|c|c|c|}
\hline Component & $\dot{E}_{D, k}[\mathrm{MW}]$ & $y_{D, k}[\%]$ & $\varepsilon_{k}[\%]$ \\
\hline Combustion Chamber & 132.70 & 27 & 82.4 \\
\hline Expander & 13.74 & 3 & 97.98 \\
\hline Flue Gas HE (1) & 6.57 & 1 & 41.65 \\
\hline Flue Gas HE (2) & 4.39 & 1 & 98.74 \\
\hline Cold Water HE & 21 & 4 & 93.26 \\
\hline ASU & 16 & 3 & 93.05 \\
\hline Overall Cycle & {$[\%]$} & 49.3 & 29.20 \\
\hline
\end{tabular}

The component with the highest exergy destruction is the combustion chamber, this is due to irreversibilities in the chemical reaction occurring within, and the mixing of streams at different temperatures. Within the combustion chamber, about $27 \%$ of the exergy of the fuel is destroyed; this implies that it is a clear candidate for improving the overall exergetic efficiency. Even a slight increase in this components exergetic efficiency will lead to a significant decrease in exergy destruction. This can be achieved by incorporating a cooling technology as described in literatures. However, the Ebsilon professional software limits the modelling of a combustion chamber and expander cooling.

Other candidates for improvement include the gas expander (over 13\% exergy destruction), the ASU, the 
series of two heat exchanger used in cooling the flue gas as shown in Fig. 2 and the heat exchanger which increases the temperature of recycle $\mathrm{CO}_{2}$ by using the heat from the compressed pure oxygen. These heat exchangers including the gas expander, however, shows high exergetic efficiency compared to the combustion chamber.

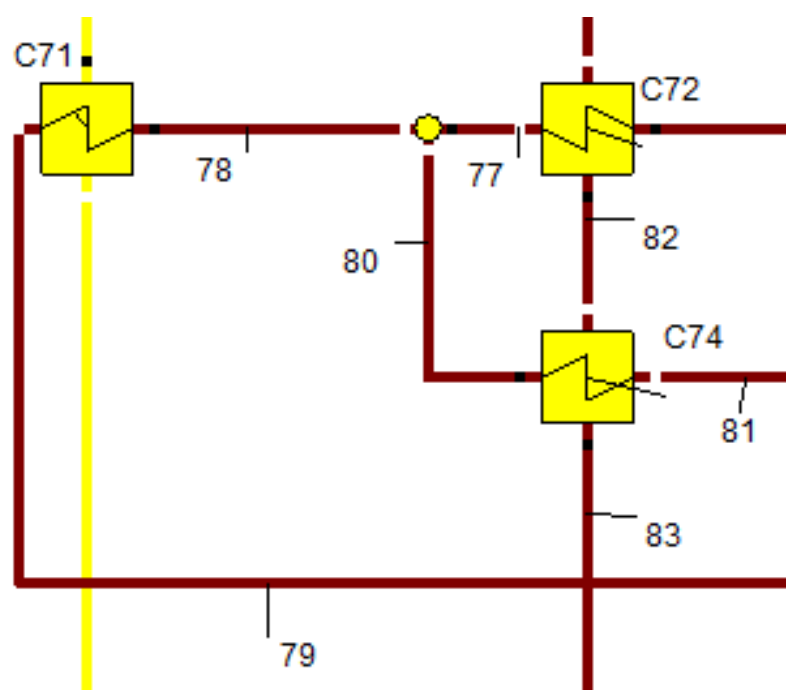

Fig. 2. Heat Exchanger with high exergy destruction rates.

\subsection{Sensitivity Analysis}

The result of the thermodynamic and exergetic analysis show that most of the important units are the combustion chamber, the expander and the heat exchangers within the cycle. Bases on this information, some important parameters are varied in orders to understand their influence on the cycle performance.

\subsubsection{ASU Specific Power Consumption}

The specific energy consumption for producing oxygen of $99.5 \%$ purity vary from literature to literature. However, in this study, the specific energy consumption of 245 $\mathrm{kWh} / \mathrm{t}$ was used according to [11]. The effect of the ASU specific energy consumption on the cycle performance is observed in this section over a range of $200-250 \mathrm{kWh} / \mathrm{t}$ and the results is shown below in Fig. 3.

The results show that the efficiency decreases with every $10 \mathrm{kWh} / \mathrm{t}$ increase in the specific power consumption by approximately $1 \%$. Invariably, the lower the specific power consumption of the air separation unit, the higher the efficiency of the plant. This unit has significant influence on the plant efficiency.

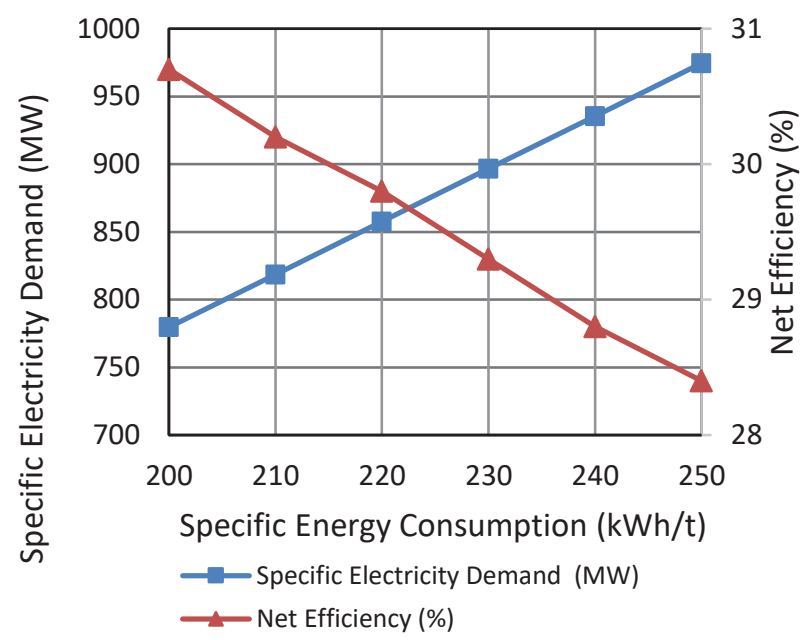

Fig. 3. Effect of Specific Power Consumption of the Air Separation Unit on the cycle performance.

\subsubsection{Turbine Inlet and outlet Pressure}

According to [11], the net efficiency of the plant increases with increased turbine inlet temperature and a fixed turbine outlet pressure. This section studies the effect of varying the turbine inlet and outlet pressure keeping the pressure ratio of the outlet to inlet constant at 10 . It also studies the effect on the $\mathrm{CO}_{2}$ recompression power demand which inevitable affects the overall cycle performance. The turbine inlet pressure was varied from 240 to 300 bar with 10 bar increase in each step as higher inlet pressures require adjustments in the heat recuperation and design of the heat exchangers. The results as shown in Fig. 4 indicates that, the lower the turbine inlet pressure, the higher the power demand for the $\mathrm{CO}_{2}$ compression and resultantly, the lower the cycle efficiency.

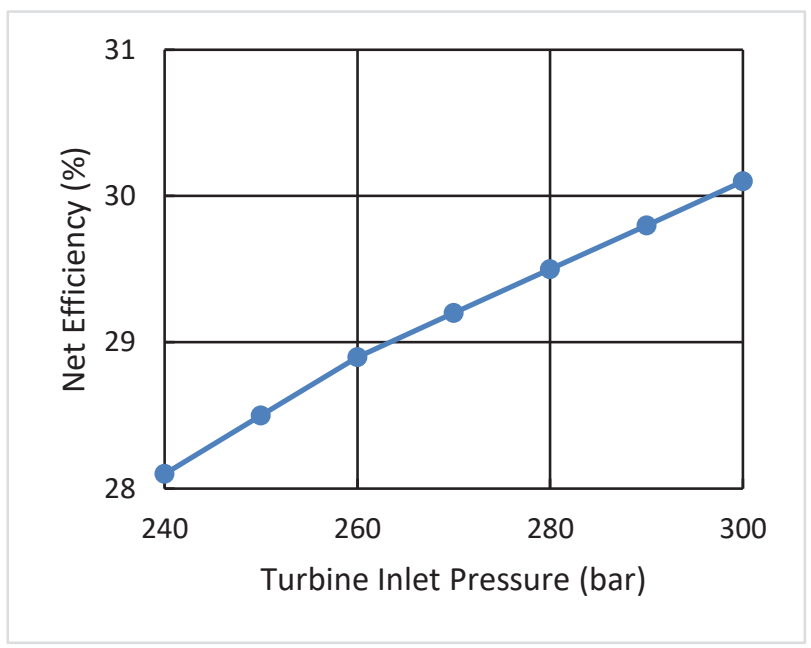

Fig. 4. Effect of varied turbine inlet and outlet pressure at a constant pressure ratio of 10 . 


\section{Conclusion}

This study modelled the coal-fired Allam cycle in Ebsilon professional software based on the limited data open to the public and subsequently, analyzes the exergetic performance of the cycle. The results obtained in terms of efficiency is considerably low (30.7\%) compared to the targeted value of above 51\% LHV reported in [5]. The major missing links, being the heat integration loops, combustion and the turbine cooling as indicated by Lu et al. [5], which have beneficial effect on the cycle performance have not been included in this study. The analyses showed that the efficiency of the simulated Allam cycle can be improved by further cooling the flue gas to near ambient temperatures; this condition will lower the work done by the compressor, the power demand which would increase the efficiency of the plant. The study also shows that the efficiency of the plant is directly related to the inefficiencies of components like the combustion chamber, gas turbine, recuperative heat exchangers and the power consumption of the air separation unit. To improve the efficiency of the plant, particular attention should be given to the above in future research.

\section{References}

1. Tracking Clean Energy Power 2019. https://www.iea.org/tcep/power/coal/

2. International Energy Agency, "21st Century Coal: Advanced Technology and Global Energy Solution," OECD/IEA, Paris, (2013). https://www.iea.org/publications/insights/insightpub lications/21stCenturyCoal FINAL WEB.pdf

3. R. J. Allam, S. M artin, B, Forrest, J. Fetvedt, X. Lu, D. Freed, G. W. Brown Jr., T. Sasaki, M. Itoh, J. Manning, "Demonstration of the Allam Cycle : An update on the development status of a high efficiency supercritical carbon dioxide power process employing full carbon capture", Energy Procedia, vol. 114, pp. 5949-5953, 2017.

4. Cheng $W-L$, Huang $W-X, N$ ian $Y-L$. Global Parameter Optimization and Criterion Formula of Supercritical Carbon dioxide Brayton Cycle with Recompression. Energy Convers Manage 2017; 150(SupplementC):669-77. http://dx.doi.org/10.1016/j.enconman.2017.08.055

5. X. Lu, B. Forrest, S. Martin, J. Fetvedt, M. M CG roddy, D. F reed, "Integration and Optimization of Coal Gasification Systems With A Near-Zero Emissions Supercritical Carbon Dioxide Power Cycle", in Proceedings of ASME Turbo Expo 2016: Turbomachinery Technical Conference and Exposition. Paper No. GT2016-58066, 2016.

6. R. J. Allam, G. W. Brown, and M. R. Palmer, "System and method for high efficiency power generation using a carbon dioxide circulating working fluid." U.S. Patent: US 8,959,887 B 2, 2015.

7. R. J. Allam, M. R. Palmer, G. W. Brown, J. E. Fetvedt, D. Freed, H. N omoto, M . Itoh, N. Okita, and
C. Jones, "High efficiency and low cost of electricity generation from fossil fuels while eliminating atmospheric emissions, including carbon dioxide," Energy Procedia, vol. 37, pp. 1135-1149, 2013.

8. R. J. Allam, J. E. Fetvedt, B. A. Forrest, and D. A. Freed, "The oxy-fuel, supercritical C O2-Allam cycle : New cycle developments to produce even lowercost electricity from fossil fuels without atmospheric emissions," in Proceedings of the ASME Turbo Expo 2014 : Power for Land, Sea and Air, Paper No. GT2014-26952, 2014.

9. M. Penkuhn, G. Tsatsaronis, "Exergy Analysis of the Allam Cycle", in The 5th International Symposium Supercritical CO2 Power Cycles, pp. 6-7, 2016.

10. N. T. W eiland, C. W. White, "Techno-economic analysis of an integrated gasification direct-fired supercritical CO2 power cycle", Fuel, vol. 212, pp. 613-625, 2018. https://www.sciencedirect.com/science/article/pii/S0 016236117312681

11. Y. Zhao, B. Wang, J. Chi, Y. Xiao, "Parametric study of a direct-fired supercritical carbon dioxide power cycle coupled to coal gasification process", Energy Conversion and Management Vol. 156, pp. 733-745, 2018. https://www.sciencedirect.com/science/article/pii/S0 196890417310968?via\%3Dihub 